\title{
Methods Used to Manage Urinary Incontinence by Older Adults in the Community
}

A. Regula Herzog, PhD, ${ }^{*}$ Nancy H. Fultz, MA, ${ }^{*}$ Daniel P. Normolle, PhD, $†$ Bruce M. Brock, PhD, and Ananias C. Diokno, $M D, \S$

This paper addresses the ways that noninstitutionalized older adults deal with involuntary urine loss. The data come from a 1983-1984 sample survey of Washtenaw County, Michigan residents aged 60 and over. Five hundred twelve self-reported incontinent respondents are included in the analyses. About a quarter of the incontinent respondents had discussed their condition with a doctor in the previous year, while $66 \%$ used one or more methods to control urine loss. Respondents preferred using absorbent products $(47 \%$ of those who used some method) and locating a toilet upon reaching a destination (42\%). Fewer respondents manipulated their voiding patterns $(29 \%)$ or diet and fluid intake $(17 \%)$, or did pelvic muscle exercises (10\%). Only $7 \%$ were taking medication for their incontinence. Logistic regression analyses were performed to identify factors associated with the choice of actions. Predictors were taken from theoretical models of health service utilization and health behavior, and included predisposing characteristics, health beliefs, enabling factors, and illness variables. Illness variables, particularly severity and type of incontinence, were the best predictors of consultation with a doctor and use of any urine control method. The predictors were less useful for understanding the choice of a specific method. J Am Geriatr Soc 37:339-347, 1989
$\mathrm{A}$ $s$ the American population ages, the management and treatment of health conditions common among older persons become of great concern. Urinary incontinence numbers among the conditions warranting such attention for several reasons. First, recent prevalence estimates indicate that about $19 \%$ of men and $38 \%$ of women 60 years of age and older living independently in the community experience involuntary urine loss to some degree. ${ }^{1} \mathrm{Sec}-$ ond, the potential costs associated with urinary incontinence include decreased morale, ${ }^{2,3}$ restricted social in-

From the *Institutes of Gerontology and Social Research, and Departments of $\nmid$ Biostatistics and §ुSurgery, The University of Michigan; and ‡Information Transfer Systems, Inc; Ann Arbor, Michigan.

Supported by the National Institute on Aging grant No. AG03742 and a grant from the AARP Andrus Foundation. Presented in an earlier version at the 40th Annual Scientific Meeting of the Gerontological Society of America, Washington, DC, November, 1987.

Address correspondence and reprint requests to A. Regula Herzog, Associate Research Scientist, Institute of Gerontology, The University of Michigan, 300 N. Ingalls, Ann Arbor, MI 48109-2007. volvement, ${ }^{4}$ rashes and skin irritation, ${ }^{5}$ higher laundry bills, ${ }^{6}$ and an increased likelihood of institutionalization. ${ }^{7}$ Third, whereas practitioners believe that up to two-thirds of incontinent persons could be cured or made more comfortable, ${ }^{8,9}$ many have not sought medical care for their condition..$^{10,11}$

Recent reviews have detailed a broad range of available methods for managing and treating urinary incontinence. ${ }^{12-14}$ These include behavior training, $a b-$ sorbent garments and pads, devices to collect urine or to prevent urine loss, medication, and surgery. Other recent studies have described the methods currently in use to treat or manage incontinence among an institutionalized population ${ }^{15}$ and among residents of senior citizen housing. ${ }^{16}$ However, patterns of treatment and management described in the medical literature, or usage found in clinical and convenience samples, cannot be generalized to all incontinent adults living in the community. Thus, it has not been established whether communitydwelling older persons are receiving the benefit of methods of urine control that could improve the quality of their lives. 
To address this question, we examined data on use of health services for urinary incontinence and personal health behaviors to control urine loss in a probability sample of noninstitutionalized older adults residing in Washtenaw County, Michigan. Specifically, this paper reports the proportion of incontinent community residents who reported having consulted a physician for incontinence problems. It also reports the proportion who described using one or more methods to manage and control their urine loss, and, of those latter individuals, the proportions using various methods.

In addition, we examined factors that might account for the consultation of a physician and for the use of urine control methods. Our selection was guided by theoretical frameworks of health service utilization and of health behavior. In particular, we considered individual-level determinants that include predisposing, enabling, and illness level (or need) characteristics. ${ }^{17,18}$ Predisposing characteristics are mainly demographic variables and health beliefs that "ready" one to take health care actions. Enabling characteristics are those factors that facilitate access to medical care, including income and having a regular doctor. Illness characteristics are the symptoms, diagnoses, and consequences of a health condition. We also made an effort to measure health beliefs traditionally associated with the Health Belief Model in the form of a person's perceptions of his/her own susceptibility to a health condition, the perceived severity of that condition, the perceived benefits of health actions, and the perceived barriers to them. ${ }^{19,20}$ All of these factors have been extensively investigated in research on general health services utilization and health behaviors. However, very little relevant work has been done on health services utilization and health behaviors regarding the specific condition of urinary incontinence.

\section{METHODS}

The data presented here were collected from August 1983 through July 1984 as one component of the Medical, Epidemiologic, and Social aspects of Aging (MESA) Project conducted at The University of Michigan. Interviewers screened a multistage stratified areaprobability sample of 13,912 Washtenaw County, Michigan households to identify all eligible persons 60 years of age or older. Of the 2,993 eligible persons identified, 1,956 agreed to be interviewed, yielding a response rate of $65 \%$. Interviewers were recruited, trained, and supervised at The University of Michigan School of Public Health. The average interview lasted 2 hours for an incontinent person, and 1.5 hours for a continent person.

The potential bias introduced by survey nonresponse was assessed by comparing age, sex, and race distributions for all MESA respondents with distributions for nonrespondents and with distributions for Washtenaw
County's older population (using Census data). Older $(75+)$ women were less likely to respond to the survey than were women aged 60 through 74 ; no age difference was observed for men. Compared to the Census information, older women were somewhat underrepresented in the MESA sample, which is consistent with the observed nonresponse pattern. Yet, when incontinence and health measures were adjusted for this form of differential nonresponse, the adjusted figures were very similar to the unadjusted ones. Major demographic characteristics of the total sample are shown in Table 1.

The analyses for the descriptive part of this paper (ie, Table 2) is based on 512 self-reported incontinent respondents who completed a full-length survey interview. An additional 74 incontinent respondents completed only an abbreviated interview that omitted a number of questions analyzed here. The analyses of the explanatory models are based on 318 self-reported incontinent respondents; the latter reduction in sample size is due to missing answers on several of the predictors used in the model. When those incontinent respondents who were included in the multivariate analyses were compared on the characteristics listed in Table 1 with those not included, they differed significantly only on age; the included incontinent subjects were younger. This suggests that the deletion of respondents with missing values introduces little systematic basis.

TABLE 1. DEMOGRAPHIC CHARACTERISTICS OF THE MESA HOUSEHOLD SAMPLE EXPRESSED AS PERCENTAGES OF THE TOTAL SAMPLE, $\mathbf{N}=\mathbf{1 , 9 5 6}$

\begin{tabular}{lr}
\hline \multicolumn{1}{c}{ Variable } & $\%$ \\
\hline Sex & \\
Males & 41.0 \\
Females & 59.0 \\
Age & \\
$60-69$ & 56.2 \\
$70-79$ & 30.1 \\
$80+$ & 13.7 \\
Race & \\
White & 91.0 \\
Black & 7.7 \\
Other & 0.4 \\
No data & 0.9 \\
Marital Status & \\
Married & 59.5 \\
Widowed & 28.6 \\
Divorced and separated & 7.9 \\
Never married & 3.8 \\
No data & 0.2 \\
Education & \\
< High school & 32.8 \\
High school & 23.8 \\
> High school & 18.6 \\
Graduated college & 24.4 \\
No data & 0.4 \\
\hline
\end{tabular}


Incontinence Status Respondents were classified as continent or incontinent based on their responses to the question, "In the past 12 months, about on how many days have you lost any urine, even a small amount, beyond your control?"' Because respondents might have been hesitant to report involuntary urine loss, those who reported no loss were asked, "Since urine loss is a main interest in our study, I want to be sure that you understand that we need to identify all occasions where urine loss occurred during the last 12 months. Are you certain that there have not been any days where you have lost any amount of urine at all?" An individual was classified as incontinent if he/she reported any days of uncontrolled urine loss, regardless of the severity of loss. However, respondents who had lost urine on less than 6 days were asked, "What do you think caused you to have lost urine on those few occasions?" and were classified as continent if the loss was due to unavoidable external factors such as a lack of restrooms.

Validity of Incontinence Measure To assess the validity of the self-report of urinary continence status, the self-reports were compared to a clinical evaluation conducted on a subset of respondents about 3 to 12 months after the survey interview at The University of Michigan Medical Center. Not all of the selected respondents agreed to participate. The examined subset is younger, better educated, and has a higher rate of urinary incontinence than those not examined. The examination included a standardized history, physical examination, and a simple provocative stress test without invasive procedures such as urodynamic studies. This information formed the basis for the clinician's impression of the incontinence status. For each sex there was a $83 \%$ agreement between the self-reports and the clinician's assessment. The agreement with the clinician's assessment of continence was $87 \%$ for women and $85 \%$ for men; the agreement with the clinician's assessment of incontinence was $79 \%$ for women, $76 \%$ for men. ${ }^{21}$

Further evidence for the reliability of the incontinence measure stems from another survey of adults in the Detroit metropolitan area in which the basic incontinence question from the MESA study (but using seven response categories of bracketed numbers of days) was asked at the beginning and the end of a 1.5 hour personal interview. Ninety-six percent agreement was obtained on the second measure with the first report of continence, $97 \%$ agreement with the first report of incontinence.

Irine-centud. Mretrods Respondents defined as incontinent were questioned about their use of various strategies, devices, and treatments for managing urine loss (see the Appendix for question wordings). From responses to these questions, the following variables were coded: 1) whether the respondent used any method of controlling involuntary urine loss; and if so, whether he/she: 2) scheduled urination, urinated before going out, or otherwise manipulated voiding behavior; 3) located the toilet upon arriving at an unfamiliar location; 4) manipulated diet and/or fluid intake; 5) exercised pelvic floor muscles; 6) used an absorbent product; and/or 7) took medication. These variables may slightly underrepresent the extent of incontinence management because respondents may have used a method of urine control when they were losing urine, but not at the time of the interview. For example, a respondent who lost urine for 2 weeks of the year before the interview due to a bladder infection would be considered incontinent. If he/she took antibiotics at that time, but stopped once the infection cleared up, he/she would not have been counted as currently taking medication.

Physician Visits for Urinary Incontinence Incontinent respondents were also asked whether they had ever discussed their incontinence with a doctor. Those who had talked with a doctor were asked when the last consultation/examination occurred.

Predictors of Physician Visits and of Use of Urinecontrol Methods Four groups of factors possibly associated with seeking the advice of a physician and the use of personal urine control methods were measured. These included predisposing characteristics, health beliefs, enabling characteristics, and illness characteristics. The grouping was used for ease of conceptualization and presentation rather than as a direct test of either Andersen's framework or the Health Belief Model. The specific predictor variables were chosen from a larger pool of possible explanatory factors. The criterion for inclusion was a correlation of at least 0.15 between a potential predictor and any of the urine-control measures or physician visit.

The predisposing characteristics are sex, age, and whether or not the respondent was widowed. The health belief questions asked, "How many of your friends and acquaintances would you say have a urine loss condition?", "How easy or difficult would you say it is for people with a urine loss condition to deal with the problem?", "How likely do you think it is that you will have a urine loss condition in the future?", and "How difficult do you think it is for people who lose urine to tell their friends and relatives about having the problem?"

The enabling characteristics are whether or not the respondent had a doctor available for urinariy pnotlremis and whether or not the respondent had hospitalization insurance. Finally, the illness characteristics include self-reported health, functional limitations, whether the respondent considered his/her own incontinence a problem, severity of incontinence, and type of incontinence. 
Some of the illness characteristics require additional explanation. The measure of functional limitations was formed as the number of functions that could be performed only with difficulty or not at all from a set of eight: getting around the house, walking up and down stairs, dressing, undressing, getting in and out of bed, bathing, using the toilet, and eating. A square root transformation was then applied to reduce the skewness of the distribution toward no functional limitations.

Two questions probed the number of days per year on which urine was lost and the amount lost on days of any loss, respectively. Respondents who reported high frequency (ie, 300 or more days of loss during the last 12 months) and/or high quantity (ie, loss of more than a quarter of a cup per day on 50 or more days during the last 12 months) were defined as severely incontinent. Those who reported low frequency (ie, 1-9 days during the last 12 months) and/or low quantity (ie, less than 0.5 teaspoon per day reported for less than 300 days during the last 12 months) were defined as mildly incontinent. Those who fell in-between were defined as moderately incontinent. This classification of severity was based on logical grounds and on comparisons of the quantity and frequency assessments with the respondents' subjective ratings of their condition in terms of nuisance, embarrassment, and distaste. More specifically, the 16 cells representing all combinations of four levels of frequency and four levels of quantity were characterized by how respondents in those cells rated their incontinence on five questions. This characterization, in turn, was used to rank the cells.

The type of incontinence was assigned according to the respondent's description of how urine loss occurred. Questions referring to urine loss preceded by an urge to void, or uncontrollable voiding with little or no warning defined urge incontinence. Questions referring to loss of urine at times of exertion such as laughing, sneezing, coughing, lifting, or bending over defined stress incontinence. Symptoms associated with urine loss of both urge and stress types defined "mixed" incontinence. The remaining incontinent respondents composed an "other" category. (The questions that compose the incontinence typology and the severity index are included in the Appendix).

Data Analysis The percentages of respondents having ever talked to a physician and those having talked to a physician during the year preceding the interview, the percentage using any form of incontinence control (versus none), and the percentage using each particular method (as a percentage of those who use at least one method) are shown in Table 2 . The percentages are shown separately for men and women because of known sex differences in patterns of incontinence. ${ }^{2}$ Chi-square tests were used to assess the significance of differences between sexes.
Because of the dichotomous nature of these urine control measures, logistic regressions were performed to examine their relation to the possible predictors. ${ }^{22}$ The groups of predictors (predisposing, belief, enabling, and illness factors) were added to the regression in a sequential fashion. Based on the following rationale, all predisposing factors were added at the first stage, followed by all health beliefs, and these were followed by all enabling factors, and finally by all illness factors. Theoretically, predisposing factors represent some of the most basic characteristics of the individual, are least malleable, and are causally most remote from the health-related behaviors. Beliefs represent fairly stable personal characteristics, that possibly affect enabling and illness factors and are affected by predisposing factors. Thus, predisposing factors should be added first to the regression, followed by beliefs, such that the explanatory contribution of the latter beyond the former can be established. Enabling factors represent access or barriers to health care services and costly products and treatments, and thus should become critical after the predisposing factors and beliefs have compelled the individual to take specific action to control urinary incontinence. Finally, illness factors represent the most proximal reason for care. Adding them last amounts to a stricter test of their relative importance beyond the other explanatory factors.

A test for the significance of each predictor group, conditional on the predictors already in the model, is listed in Table 3 . The statistic tests the hypothesis that, after the conditional variables have been entered in the logistic regression model, the predictor group of interest does not add to the predictive power of the model. First, the standard $\chi^{2}$ goodness-of-fit statistic is calculated on the logistic regression model including only the conditional predictor variables (these appear in Table 3 to the right of the vertical bar in the row headings). Then, the same statistic is calculated on the model which contains the conditional predictors plus the predictors of interest. The measure of significance is the difference between these two statistics. The number of degrees of freedom of the test equals the difference in the number of coefficients estimated in the two models, and is listed under the row heading.

The contributions of the predictors, evaluated with reference to logit coefficients and associated significance levels, are not shown here but are used to guide the presentation of findings. They are available upon request. For some of the significant predictors, the relationships to the dependent variables are shown in tabular form for ease of comprehension (Tables 4: and 5).

When evaluating the results, it is important to realize that they come from respondents' reports of methods used to control incontinence. Therefore, they cannot be taken as entirely valid indicators of physicians' recommendations for their incontinent patients or of the qual- 
ity of care existing in the community. It is also important to note that the data are cross-sectional and cannot be used to confirm hypotheses about causality that underlie the analysis and discussion.

\section{RESULTS}

Incontinence Status Thirty percent of all 1,956 respondents reported any urine loss within the last 12 months; the prevalence for men was $19 \%$, and for women $38 \%$. The $38 \%$ incontinent women can further be differentiated into $4 \%$ urge type, $10 \%$ stress type, $21 \%$ combined urge and stress, and $3 \%$ other. The $19 \%$ incontinent men divided into $7 \%$ urge, $2 \%$ stress, $5 \%$ mixed, and $5 \%$ other. In terms of severity, there were $16 \%$ mildly, $9 \%$ moderately, and $7 \%$ severely incontinent women ( $6 \%$ could not be categorized); the corresponding percentages for men were $10 \%, 4 \%$, and $2 \%$, with $3 \%$ not classified.

Patterns of Use In terms of health service utilization, only about one-quarter of all incontinent respondents had talked with a doctor about urinary incontinence in the year preceding the survey interview (Table 2). Further, only about half of all incontinent respondents had ever talked with a doctor about the condition. These patterns did not differ for men and women.

In terms of control measures, about two-thirds of the respondents reported using at least one method. Women were significantly more likely than men to be using any method to control urine loss; about $69 \%$ reported doing so, as compared to about $55 \%$ of the men. For those respondents who attempted to manage their incontinence, absorbent products such as sanitary napkins, toilet tissue, and absorbent garments were the

TABLE 2. PERCENTAGES OF OLDER INCONTINENT ADULTS IN THE COMMUNITY USING DIFFERENT URINE CONTROL METHODS

\begin{tabular}{lccc}
\hline & Total & Male & Female \\
\hline Ever talked with doctor & 54 & 48 & 56 \\
Talked with doctor in past & 23 & 22 & 24 \\
$\quad$ year & 66 & 55 & $69 \dagger$ \\
Used any method & & & \\
Method used: & 47 & 20 & $55 \dagger$ \\
$\quad$ Absorbent products & 42 & 43 & 42 \\
Locate the toilet & 29 & 31 & 28 \\
$\quad$ Voiding manipulation & 17 & 20 & 16 \\
$\quad$ Diet/fluid manipulation & 10 & 4 & $12 *$ \\
$\quad$ Pelvic muscle exercises & 7 & 10 & 6 \\
$\quad$ Medications &
\end{tabular}

"Used any Method" and "Talked with Doctor in Past Year" are based on all incontinent respondents who answered the full length questionnaire: 134 men and 378 women. The other variables are based on those respondents who used any method: 74 men and 262 women. Percentages do not sum to $100 \%$ because responents may have used more than one method of urine control.

${ }^{*} \mathrm{P}<.05 ; \uparrow \mathrm{P}<.001$. most popular means. Almost half of the incontinent respondents that used any urine control method used this type of product. There was, however, a large difference between men's and women's usage. While $55 \%$ of the women used absorbent products, only about $20 \%$ of the men used them.

The next most common means of controlling incontinence was to locate a toilet upon arrival at an unfamiliar place. Forty-two percent of the respondents that used any method of urine control chose this strategy, and there was no significant sex difference. Voiding manipulation was practiced by $29 \%$ of the incontinent respondents who attempted to control their condition. This includes scheduled urination, urination before leaving home, and other conscious efforts to plan urination. Again, there was no significant difference between men's and women's use of this method of management.

Fewer respondents altered their diets and/or fluid intake to control incontinence ( $17 \%$ of those who used some method), or did pelvic muscle exercises $(10 \%)$. Women $(12 \%)$ were significantly more likely to do pelvic muscle exercises than were men $(4 \%)$. There was no sex difference for diet/fluid manipulation. The finding that only $7 \%$ of the respondents were using medication as their means of urine control is consistent with low use of physician advice discussed above.

Explanations of Use We turn now to results of the logistic regression analyses for three behaviors - the health service utilization measure of whether a physician was consulted during the year preceding the interview, and the personal health behaviors of whether any method at all was used and whether absorbent products were used. For the remaining five control behaviors, the logistic regression analyses did not account for a significant amount of variance, and thus the results are not presented or further discussed. The other health service utilization measure, whether a physician was ever consulted, was ambiguous in its temporal sequence with the predictors and was not used in the multivariate analysis for this reason.

Talking to a Physician. While predisposing factors do not appear to contribute to the explanation of recent contacts with a physician for incontinence problems, beliefs about urinary incontinence do, as suggested by the significant conditional $\chi^{2}$ (Table 3 ). In particular, the belief about the prevalence of urinary incontinence among friends appears significantly related to seeking a physician's care. Respondents who reported higher numbers of incontinent friends were more likely to have talked to a physician. Enabling factors contribute further to an explanation of the contact with a physician. The critical enabling variable is whether the respondent has a doctor for urinary problems. If so, he or she was more likely to have talked about urinary problems.

Finally, illness factors contribute to the explanation. 
TABLE 3. SUMMARY OF LOGISTIC REGRESSIONS FOR URINE CONTROL METHODS

\begin{tabular}{|c|c|c|c|}
\hline \multirow[b]{2}{*}{$\begin{array}{c}\text { Predictor } \\
\text { (Degrees of Freedom) }\end{array}$} & \multicolumn{3}{|c|}{$\begin{array}{c}\chi^{2} \text { Significance Statistic } \\
\text { (Cumulative Predictive Accuracy) }\end{array}$} \\
\hline & $\begin{array}{l}\text { Talked with Doctor } \\
\text { In Past Year } \\
(\mathbf{n}=\mathbf{3 1 8})\end{array}$ & $\begin{array}{c}\text { Any } \\
\text { Method } \\
(\mathbf{n}=\mathbf{3 1 8})\end{array}$ & $\begin{array}{l}\text { A.bsorbent } \\
\text { Products } \\
\text { (n= 209) }\end{array}$ \\
\hline $\begin{array}{l}\text { Predisposing } \\
\text { (3) }\end{array}$ & $\begin{array}{c}2.57 \\
(.745)\end{array}$ & $\begin{array}{l}10.13^{*} \\
(.682)\end{array}$ & $\begin{array}{l}22.24 \dagger \\
(.603)\end{array}$ \\
\hline Beliefs $^{c} /$ Predisposing $^{2}$ & $12.48^{*}$ & $38.77 \dagger$ & $9.61^{*}$ \\
\hline (4) & (.739) & $(.686)$ & $(.656)$ \\
\hline Enabling $/$ (Beliefs + Predisposing) & $22.88 \dagger$ & 2.21 & $9.32 \dagger$ \\
\hline (2) & $(.777)$ & $(.698)$ & $(.675)$ \\
\hline $\begin{array}{l}\text { Illness }{ }^{e} / \text { (Enabling, Beliefs + Predisposing) } \\
\text { (7) }\end{array}$ & $\begin{array}{l}19.22 \dagger \\
(.805)\end{array}$ & $\begin{array}{l}24.01 \dagger \\
(.717)\end{array}$ & $\begin{array}{l}26.24 \dagger \\
(.708)\end{array}$ \\
\hline
\end{tabular}

- The $\chi^{2}$ statistic is a measure of significance of the first predictor in the row, conditioned on the other variables in the row, derived from a goodness-of-fit statistic; the cumulative predictive accuracy is the proportion of incontinent respondents correctly classified by the logistic regression model including all the predictors in the row.

' Sex, Age, Widowhood.

' Number of incontinent friends, Difficulty of dealing with incontinence, Likelihood of being incontinent in the future, Difficulty of telling about one's incontinence.

'Having a doctor for urinary problems, Having hospitalization insurance.

- Self-reported health, Functional limitations, Severity of incontinence, Whether own incontinence is defined as a problem.

$* \mathrm{P}<.05 ; \mathrm{P}<0.01$.

Specific variables of importance are severity (Table 4) and type of urinary incontinence (Table 5). Respondents with severe incontinence and those with stress-type incontinence were more likely to have talked to a physician than those with mild incontinence or types other than stress. Separate logistic regressions for men and women revealed that stress incontinence was significant only among men, while severity was significant for both sexes.

Using Any Method of Urine Control. The major sets of factors that contribute to explaining whether the individual used any of the means to gain control over urine loss (listed in Table 2) are beliefs, illness factors, and to a lesser extent predisposing factors (Table 3). Respondents who think that urinary incontinence is easy to deal with are more likely to use one or more methods to control their incontinence. While this relationship is op- posite to what would be predicted by the standard Health Belief Model, it is possible that the use of control measures has led to the perception of incontinence as a problem that is easy to deal with; however, with crosssectional data, as used here, we cannot determine the direction of causation. Also, respondents who think that they are likely to be afflicted with incontinence in the future are more likely to use one or more control methods than those who think it unlikely. Male respondents who are older are more likely to use control methods. Finally, respondents who have relatively severe incontinence, and those who have a stress or mixed type are more likely to use a control method than those who have milder incontinence, or an urge type (Tables 4 and 5).

Using Absorbent Products. Predisposing factors contribute to the explanation of whether any absorbent product

TABLE 4. PERCENTAGES OF OLDER INCONTINENT ADULTS USING URINE CONTROL METHODS, BY SEVERITY

\begin{tabular}{|c|c|c|c|}
\hline & \multicolumn{3}{|c|}{ Incontinence Severity } \\
\hline & Mild & Moderate & Severe \\
\hline \multicolumn{4}{|l|}{ Females } \\
\hline Talked with doctor in past year & 18.9 & 25.7 & 41.8 \\
\hline Any method & 55.9 & 72.9 & 89.1 \\
\hline Absorbent products & 24.3 & 35.7 & 72.7 \\
\hline (n) & 111 & 70 & 55 \\
\hline \multicolumn{4}{|l|}{ Males } \\
\hline Talked with doctor in past year & 12.0 & 30.4 & 66.7 \\
\hline Any method & 48.0 & 65.2 & 88.9 \\
\hline Absorbent products & 4.0 & 13.0 & 66.7 \\
\hline (n) & 50 & 23 & 9 \\
\hline
\end{tabular}


TABLE 5. PERCENTAGES OF OLDER INCONTINENT ADULTS USING URINE CONTROL METHODS, BY TYPOLOGY

\begin{tabular}{lcccc}
\hline & \multicolumn{3}{c}{ Incontinence Typology } \\
\cline { 2 - 4 } & Urge & Stress & Mixed & Other \\
\hline Females & & & & \\
$\quad$ Talked with doctor in past year & 20.0 & 20.6 & 29.9 & 18.2 \\
Any method & 46.7 & 60.3 & 76.9 & 36.4 \\
Absorbent products & 20.0 & 34.9 & 44.9 & 9.1 \\
(n) & 15 & 63 & 147 & 11 \\
Males & 20.0 & 44.4 & 28.6 & 13.6 \\
Talked with doctor in past year & 56.7 & 77.8 & 66.7 & 9.9 \\
Any method & 3.3 & 11.1 & 33.3 & 9.1 \\
Absorbent products & 30 & 9 & 21 & 22 \\
(n) & & & & \\
\hline
\end{tabular}

is used (Table 3). The critical variable in this category is sex. As noted before, women were more likely than men to turn to such products for their incontinence problem. Illness factors represent another clear set of contributing factors. Among them, only severity is significant. The relationship between severity and the use of absorbent products is displayed in Table 4 . Because men's and women's differential use of absorbent products is confounded with the severity and the type of incontinence, ${ }^{1}$ the effect of sex is insignificant when illness factors are included as predictors in the regression.

\section{DISCUSSION}

Data from the MESA Project provide a unique opportunity to document the seeking of physician care for urinary incontinence and the utilization of management methods for the condition among a probability sample of noninstitutionalized older persons. While the limitations of self-reported and cross-sectional data are recognized, findings from this study should be less limited by sampling biases than those from previous research in this area.

The small proportion of incontinent respondents $(23 \%)$ who have recently seen a physician for their problem is disturbing, given the increasing sophistication of medical treatment for incontinence. Those with severe incontinence are more likely to have consulted a physician than those with a mild condition.

The popularity of absorbent products as a method of urine control is also disturbing because it suggests the widespread use of a method that should only be used after more satisfactory methods have been exhausted. Starer and Libow ${ }^{15}$ detail a number of potential drawbacks to the use of "diaper"-like garments, including loss of dignity, skin breakdown, expense, and the reduced likelihood of (further) medical attention.

In light of these findings, it becomes particularly important to understand why some incontinent individuals seek formal health care services or choose specific methods of management, while others do not. Illness factors are clearly the most powerful explanation for physician visits and specific methods that were examined in this paper. Particularly, the severity of the condition, but also its type, are related to whether a physician was consulted, whether any control measures had been adopted, and whether absorbent products were being used. This finding is consistent with existing literature on more general health care utilization and health behavior among the elderly, where illness factors like self-rated health status and functional impairment are typically found to relate to the use of formal services such as physicians, hospitals, or social services, as well as informal care behaviors such as days spent in bed or days of restricted activities. ${ }^{23-26}$ However, unlike other investigations where illness factors are usually entered first into the analysis and, thus account for all the variance shared with other predictors, in the present investigation illness factors were added in the last step so that the conditional $\chi^{2}$ reflects only the unique variance accounted for by illness factors. Therefore, while this analysis represents a more conservative test of the contribution of illness factors, they still demonstrate their relative importance. The findings that severity of urine loss is a significant predictor of health care utilization and personal health behaviors is interesting because in our study, as reported elsewhere, severity had a relatively minor effect on psychological distress. ${ }^{2}$

It is also noteworthy that enabling factors do not appear to be important explanatory variables; income was not sufficiently associated with any outcome to justify its inclusion in the multivariate analysis. The minor role of enabling factors is consistent with the literature on health service utilization, but the explanation for the minor role given in this literature does not apply to the use of absorbent products. That is, it is often claimed that the comprehensive coverage of Medicare has removed financial and other access barriers. However, absorbent products are only partly covered by third party coverage, thus their cost may be expected to represent a barrier for low-income elderly. This hypothesis was not supported.

Noteworthy, furthermore, is the fact that beliefs 
about urinary incontinence did not contribute in any major way to health services utilization and personal control measures. Twelve questions probed the standard dimensions of the Health Belief Model. Except for four of them, their correlations with methods for controlling incontinence were too low to warrant inclusion in the multivariate analyses.

Because the patterns of usage of some methods differ by sex (Table 2), logistic regression analyses were also conducted separately for men and women. The patterns were rather similar across sex. The major differences were that the age effect on the use of any method and on the use of absorbent products remained significant only for men. Finally, the effects of stress incontinence on seeing a doctor and on using any method remained significant only for men, as mentioned above. This latter sex difference may reflect men's lesser familiarity with stress incontinence and, thus, their greater concern that leads them to consult a doctor. Otherwise, sex differences were relatively minor, although this could be due in part to the small sample size for men.

To summarize, this paper has shown that about twothirds of all respondents classified as incontinent by the MESA definition do attempt to manage their incontinence. The most common strategies are the use of $a b-$ sorbent products, the location of toilets before the need to urinate arises, and the manipulation of voiding patterns. In contrast, only about one-quarter have sought formal health care regarding the condition in the past year, only about half have ever sought such care, and very few were taking any medication for the condition. Those respondents with the more severe incontinence and those with stress type are more likely to have talked to a physician about their incontinence and to use any of the control methods.

These findings suggest that health care professionals must become aware of the likely prevalence of urinary incontinence among their patients. Because of patients' hesitancy to mention incontinence-related symptoms, discussion of the topic should be initiated by health care professionals during routine visits. Although severe symptoms are more likely to be brought to a doctor's attention, treatment should ideally begin before the condition becomes severe. Incontinent persons must also learn that the condition can be treated or controlled through more effective methods than the absorbent products and preoccupation with toileting chosen by many. Again, health care professionals have an important role to play in promoting such public education.

\section{ACKNOWLEDGMENTS}

The authors thank Morton Brown, John DeLancey, Neal Krause, Jeffrey Levin, and Nancy Whitelaw for many useful suggestions on the paper.

\section{REFERENCES}

1. Diokno AC, Brock BM, Brown MB, et al: Prevalence of urinary incontinence and other urological symptoms in the non-institutionalized elderly. J Urology 136:1022, 1986

2. Herzog AR, Fultz NH, Brock BM, et al: Urinary incontinence and psychological distress among older adults. Psychology and Aging 3:115, 1988

3. Wyman JF, Harkins SW, Choi SC, et al: Psychosocial impact of urinary incontinence in women. Obstet Gynecol 70:378, 1987

4. Norton $C$ : The effects of urinary incontinence in women. International Rehabilitation Medicine 4:9, 1982

5. Ouslander JG: Urinary incontinence in the elderly. Western J Med 135:482, 1981

6. Dobson P: Management of incontinence in the home. London, The Disabled Living Foundation, 1974

7. Weissert $W$, Scanlon W: Determinants of institutionalization of the aged. Working paper no. 1466-21. Washington, DC, The Urban Institute, 1982

8. Fossberg E, Sander S, Beisland HO: Urinary incontinence in the elderly: A pilot study. Scand J Urol Nephrol (Suppl) 60:51, 1981

9. Willington FL: Urinary incontinence: A practical approach. Geriatrics 35:41, 1980

10. Thomas TM, Plymat KR, Blannin J, et al: Prevalence of urinary incontinence. Br Med J 281:1243, 1980

11. Yarnell JWG, St Leger AS: The prevalence, severity and factors associated with urinary incontinence in a random sample of the elderly. Age Ageing 8:81, 1979

12. Ouslander J, Kane R, Vollmer S, et al: Technologies for managing urinary incontinence, OTA-HCS-33. Washington, DC, US Congress, Office of Technology Assessment, 1985

13. Resnick NM, Yalla SV: Management of urinary incontinence in the elderly. N Engl J Med 313:800, 1985

14. Williams ME, Pannill III FC: Urinary incontinence in the elderly: Physiology, pathophysiology, diagnosis, and treatment. Ann Intern Med 97:895, 1982

15. Starer P, Libow LS: Obscuring urinary incontinence: Diapering of the elderly. J Am Geriat Soc 33:842, 1985

16. Mitteness LS: The management of urinary incontinence by community-living elderly. Gerontologist 27:185, 1987

17. Andersen RM: A behavioral model of families' use of health services. Chicago, University of Chicago Press, 1968

18. Andersen R, Newman JF: Societal and individual determinants of medical care utilization in the United States. Milbank Mem Fund Q 51:95, 1973

19. Janz NK, Becker MH: The Health Belief Model: A decade later. Health Education Quarterly 11:1, 1984

20. Rosenstock IM: Historical origins of The Health Belief Model. Health Education Monographs 2:328, 1974

21. Diokno $\mathrm{AC}$, Brown MB, Brock BM, et al: Clinical and cystometric characteristics of continent and incontinent non-institutionalized elderly. J Urology 140:567, 1988 
22. Cleary PD, Angel R: The analysis of relationships involving dichotomous dependent variables. J Health Soc Behav 25:334, 1984

23. Coulton $C$, Frost $A K$ : Use of social and health services by the elderly. J Health Soc Behav 23:330, 1982

24. Evashwick C, Rowe G, Diehr P, et al: Factors explaining the use of health care services by the elderly. Health Services Research 19:357, 1984
25. Wolinsky FD, Coe RM: Physician and hospital utilization among noninstitutionalized elderly adults: An analysis of the Health Interview Survey. J Gerontol 39:334, 1984

26. Wolinsky FD, Coe RM, Miller DK, et al: Health services utilization among the noninstitutionalized elderly. J Health Soc Behav 24:325, 1983

\section{APPENDIX. QUESTIONS ABOUT INCONTINENCE MANAGEMENT, TYPOLOGY, AND SEVERITY}

The respondents' methods of managing incontinence were coded from the following questions:

Do you have a regular schedule that you usually use to get you to the toilet to urinate, for example every hour or so? (yes/no) When you go into a new place, do you find out where the nearest toilet is soon after you arrive or do you wait until you feel the need to use the bathroom, then try to locate it? (find toilet soon/wait)

Please tell me exactly what medical treatments the doctor recommended or prescribed for your urine loss condition? ( $(\longrightarrow$ ) Does that include all medicines your doctor has prescribed or recommended? (yes/no) Does that include any specific bladder control products like special absorbent underclothes or pads recommended by a doctor? (yes/no) Does that include any special bladder or pelvic muscle exercises that might have been recommended by a doctor? (yes/no) Does that include any recommendations by a doctor to change any habits like how much liquid you should drink or when to avoid liquids or how often to urinate? (yes/no)

Do you ever use any types of absorbent underpads, adult wetness control or diaper-like garments, female sanitary products, toilet or facial tissues, or anything else for your condition? (yes $/ \mathrm{no}$ )

Is there anything else you do on your own that helps you deal with your urine loss condition? (yes/no) (IF YES) What do you do? (

The next questions were used to construct the incontinence typology and severity index:

\section{Incontinence typology}

Stress incontinence.

Does coughing gently ever cause you to lose urine? (yes/no)

Coughing hard? (yes/no)

What about sneezing? (yes/no)

Lifting things? (yes/no)

Bending over? (yes/no)

What about vomiting? (yes/no)

Might straining to do something like opening a jar or pulling a heavy object cause you to lose urine? (yes/no)

What about laughing? (yes/no)

Sexual activity? (yes/no)

Walking briskly or jogging? (yes/no)

Urge incontinence.

What about finding the toilet is occupied and you are delayed in getting to use it? (yes/no)

What about suddenly having the feeling that your bladder is very full? (yes/no)

Some people receive very little warning and suddenly find that they are losing or are about to lose urine beyond their control. How often does this happen to you? (often/ sometimes/ rarely/ never)

If you can't find a toilet, and you have an urge to urinate, how often do you end up losing urine and wetting yourself? (often/ sometimes/ rarely/ never)

Now I'd like to ask about your urinary habits in some detail. In general, over a 24-hour period, about how many times do you go to the toilet and urinate? (\# of times)

Do you ever have trouble getting to the bathroom on time? (yes/no)

\section{Severity index}

In the past 12 months, about on how many days have you lost any urine, even a small amount beyond your control? (\# of days)

Using the measuring devices again, altogether, over the course of an entire day, that is over a 24-hour period, in total how much urine would you say that you lose without control when you are having problems? (quantity) 